\title{
E3 ubiquitin ligase Smurf2: a prognostic factor in microsatellite stable colorectal cancer
}

This article was published in the following Dove Medical Press journal: Cancer Management and Research

\author{
Fee Klupp' \\ Christina Giese' \\ Niels Halama ${ }^{2}$ \\ Clemens Franz' \\ Felix Lasitschka ${ }^{3,4}$ \\ Arne Warth ${ }^{3}$ \\ Thomas Schmidt ${ }^{1}$ \\ Matthias Kloor ${ }^{5}$ \\ Alexis Ulrich' \\ Martin Schneider \\ 'Department of General, Visceral and \\ Transplantation Surgery, University \\ of Heidelberg, Heidelberg 69I20, \\ Germany; ${ }^{2}$ National Center for \\ Tumor Diseases, Medical Oncology \\ and Internal Medicine VI, Tissue \\ Imaging and Analysis Center, Bioquant, \\ University of Heidelberg, Heidelberg \\ 69120, Germany; ${ }^{3}$ Institute of \\ Pathology, University of Heidelberg, \\ Heidelberg 69I20, Germany; ${ }^{4} \mathrm{~T}$ issue \\ Bank of the National Center for \\ Tumor Diseases, Heidelberg 69I20, \\ Germany; ${ }^{5}$ Department of Applied \\ Tumor Biology, German Cancer \\ Research Center, Heidelberg 69120, \\ Germany
}

Correspondence: Martin Schneider Department of General, Visceral and Transplantation Surgery, University of Heidelberg, Im Neuenheimer Feld I I0, Heidelberg 69120, Germany

Tel +49622I 5637876

Fax +49 622I 565506

Email martin.schneider@med.uniheidelberg.de
Purpose: Smurf2 is a member of the homologous to E6-AP carboxyl terminus family of E3 ubiquitin ligases. Changes in their expression pattern are known to contribute to tumorigenesis. Smurf2 plays a decisive role in cell differentiation, proliferation, and migration and exhibits a dual role in cancer - functioning as both oncogene and tumor suppressor. Dysregulation of Smurf2 in different cancer types has been described, besides colorectal cancer (CRC). We therefore examined the expression and oncogenic potential of Smurf2 in human CRC patients.

Materials and methods: Expression levels of Smurf2 were analyzed via qRT-PCR in CRC specimens and healthy mucosa from 98 patients who had undergone surgery due to CRC. Spatial expression of Smurf2 was additionally studied by immunohistochemistry. siRNA-mediated knockdown of Smurf2 was applied for migration and invasion assays in DLD-1 and SW-480 cells. Results: Smurf2 was significantly overexpressed in CRC tissue compared to corresponding healthy colon mucosa. Smurf2 expression levels differed significantly between microsatellite instable (MSI) and microsatellite stable (MSS) CRC. In patients suffering from MSS CRC, high tumoral expression of Smurf2 was significantly associated with impaired overall survival. Consistently, in vitro analysis revealed that knockdown of Smurf2 reduced the invasive and migratory potential of MSS CRC cells.

Conclusion: Smurf2 expression is upregulated in CRC specimens and affects survival dependent on patients' MSI status. Moreover, Smurf2 supports cancer cell migration and invasion, collectively suggesting an oncogenic function in CRC.

Keywords: Smurf2, colorectal cancer, MSS status, prognosis, biomarker

\section{Introduction}

The ubiquitin-proteasome system (UPS) is required for protein degradation through protein ubiquitination. ${ }^{1}$ Protein ubiquitination by the UPS plays a substantial role in a variety of cellular processes such as differentiation, proliferation, DNA repair, signal transduction and transcription, angiogenesis, and apoptosis. ${ }^{2-4}$ The UPS consists of ubiquitin-activating enzyme E1, ubiquitin-conjugating enzyme E2, and a substrate-specific E3 ubiquitin ligase. ${ }^{1}$ Dysregulation in the expression pattern of the substrate-specific E3 ubiquitin ligases is known to contribute to tumorigenesis. ${ }^{1} \mathrm{Smad}$ ubiquitination regulatory factor 2 (Smurf2) belongs to the homologous to E6-AP carboxyl terminus (HECT) family of E3 ubiquitin ligases. ${ }^{5}$ It displays a contradictory role in cancer exhibiting both tumorsuppressive and oncogenic functions. ${ }^{2,6,7}$ Tumor suppressive functions of Smurf2 are linked to strengthening of p53 and p21, resulting 
in cell cycle senescence. ${ }^{3}$ By contrast, Smurf2 leads to tumor progression and promotes metastases via upregulation of epithelial-to-mesenchymal transition markers such as N-cadherin. ${ }^{3}$ Moreover, Smurf2 inhibits apoptosis due to mouse double minute 2 homolog-(MDM2) mediated inhibition of p53. ${ }^{8}$ Importantly, as a member of the UPS, E3 ligase Smurf2 leads - along with its binding partner Smad7 - to TGF- $\beta$ receptor degradation. It modulates TGF- $\beta$ pathway signaling by regulating the degradation of Smad1, Smad2, and Smad3, thus promoting cancer progression via altered TGF- 3 signaling. ${ }^{5,9,10}$

Altered expression of Smurf2 has been observed in a variety of solid cancer types, such as breast or esophageal cancer. ${ }^{7,11,12}$ Given its function in the above mentioned signaling pathways, it is not astonishing that Smurf2 silencing diminishes the invasion and migration of breast cancer cells. ${ }^{12}$ Besides, high-level expressional changes of Smurf2 are associated with poor prognosis in esophageal cancer. ${ }^{11}$ Nonetheless, until now, no data exist regarding Smurf2 expression and its oncogenic relevance in CRC patients. Therefore, we examined Smurf2 expression levels in a collective of $98 \mathrm{CRC}$ patients, comparing colorectal carcinoma tissue with corresponding healthy mucosa. Subsequently, Smurf2 expression levels were compared with clinical data including overall survival. The impact of Smurf2 expression on cancer cell migration and invasion was additionally assessed applying siRNA-mediated knockdown in DLD-1 and SW-480 CRC cells.

\section{Materials and methods Patients and tissue samples}

Ninety-eight patients suffering from colorectal cancer (CRC) who underwent surgery at the Department of General, Visceral and Transplantation Surgery, University of Heidelberg, Germany, between 2007 and 2013 were included. Fresh frozen tissue specimens of healthy mucosa and colorectal carcinomas were used for qRT-PCR. Healthy mucosa tissue was sampled at least $10 \mathrm{~cm}$ distant from the tumor. Formalin-fixed paraffinembedded tissue samples of colorectal carcinoma and corresponding healthy colon mucosa were provided from the tissue bank of the National Center for Tumor Disease, University of Heidelberg, Germany for immunohistochemical staining. Every patient gave written informed consent and the local ethics committee of the University Heidelberg approved the study. Clinical and histopathological characteristics including date of birth, gender, tumor location, TNM classification, UICC (Union internationale contre le cancer) stage, R classification, grading, neoadjuvant radiochemotherapy, adjuvant chemotherapy, microsatellite stability (MSS) status, postoperative complications, and overall survival (time from operation up to death or last follow-up) were obtained from each patient.

\section{RNA isolation and qRT-PCR}

Total RNA from tumor tissue and corresponding healthy mucosa was isolated using RNeasy ${ }^{\circledR}$ Mini Kit (Qiagen, Hilden, Germany) and reverse-transcribed using ImProm-II ${ }^{\mathrm{TM}}$ Reverse Transcription System (Promega, Mannheim, Germany) according to the manufacturer's instructions. Resulting cDNA was amplified and detected with LightCycler $^{\circledR}$ 480 SYBR Green I Master (Roche Diagnostics GmbH, Mannheim, Germany) in a Roche Light Cycler ${ }^{\circledR} 480$ System (Roche Diagnostics GmbH). Predesigned primers of Smurf2 (HS_SMURF2_1_SG QuantiTect Primer Assay) and 18S (HS_RRN18S_1_SG QuantiTect Primer Assay) were purchased from Qiagen (sequences available on request).

\section{Immunohistochemistry}

Slides were pretreated at $\mathrm{pH}$ 9.0, and immunohistochemical staining of $5 \mu \mathrm{m}$ thick formalin-fixed paraffin-embedded slides of CRC tissue and corresponding healthy mucosa for Smurf2 (Anti-Smurf2 ab38543, Abcam, Cambridge, UK) was performed using the Dako autostainer with 1:200 dilution. A board certified pathologist from the Institute of Pathology, University of Heidelberg performed histopathological assessment.

\section{Cell culture and transfection}

DLD-1 (ATCC ${ }^{\circledR}$ CCL-221 ${ }^{\mathrm{TM}}$, LGC Standards GmbH, Wesel, Germany) and SW480 (ATCC ${ }^{\circledR}$ CCL-228 ${ }^{\mathrm{TM}}$, LGC Standards $\mathrm{GmbH}) \mathrm{CRC}$ cells were used for in vitro studies. Both cell lines were cultured in RPMI-1640 (Sigma-Aldrich GmbH, Munich, Germany), supplemented with 10\% FBS (Gibco ${ }^{\circledR}$ by Life Technologies, Darmstadt, Germany), 100 U/mL penicillin, and $100 \mu \mathrm{g} / \mathrm{mL}$ streptomycin (Sigma-Aldrich $\mathrm{GmbH})$ at $37^{\circ} \mathrm{C}$ and $5 \% \mathrm{CO}_{2}$.

Smurf2 siRNA (Stealth ${ }^{\mathrm{TM}}$ RNAi Smurf2 HSS127687) and scrambled siRNA as a control nonsilencing sequence (Stealth ${ }^{\text {TM }}$ RNAi Negative Control, both from Life Technologies GmbH, Darmstadt, Germany) were transfected using Lipofectamine ${ }^{\circledR}$ RNAiMAX (Life Technologies $\mathrm{GmbH}$ ) according to the manufacturer's protocol. Transfection efficiency was monitored with semiquantitative RT-PCR and calculated as the difference between siControl and the residual Smurf2 expression after transfection for each invasion and migration assay separately. 


\section{Cell migration and invasion assays}

Twenty-four hours after transfection, DLD-1 and SW-480 cells were harvested and starved in serum-free medium prior to experiments. Migration and invasion assays were performed using ThinCerts $^{\mathrm{TM}}$ ( 24 wells, pore size $8.0 \mu \mathrm{m}$, Greiner Bio-One, Frickenhausen, Germany) and BD BioCoat $^{\mathrm{TM}}$ Matrigel $^{\mathrm{TM}}$ Invasion Chambers (Greiner BioOne), respectively, according to manufacturer's protocol. Incubation time was 24 hours for cell migration and 72 hours for cell invasion assay. Readouts were determined by spectrophotometric readings on a microtiter plate at 540 $\mathrm{nm}$ with a microplate reader. Both assays were performed in triplicate.

\section{Statistics}

Statistical analyses were conducted with Excel 2013 (Microsoft Corporation, Redmond, WA, USA) and SPSS, version 22 (SPSS, IBM Corporation, Armonk, NY, USA). Paired Student's $t$-test was used to determine expressional differences in different tissues. Expressional data are presented as mean + standard error of the mean. Expressional differences of Smurf2 in MSS vs microsatellite instable (MSI) tumors were assessed using Mann-Whitney $U$-test. Statistical differences of clinical parameters such as $\mathrm{T}$ stage, $\mathrm{N}$ stage, grading, resection margin, tumor site, surgical procedure, and localization of recurrence were assessed with Kruskal-Wallis test. Statistical differences of clinical parameters such as gender, age, M stage, liver metastases, neoadjuvant chemotherapy, anastomotic leakage, microsatellite stage, recurrence, and primary stoma were assessed using Mann-Whitney $U$-test. Median follow-up time was calculated as median difference between time of operation and last follow-up or death of patients. Kaplan-Meier method was employed to estimate cancer-related overall survival. Differences between survival curves were evaluated by log-rank test. Results were considered significant at a $P$-value $<0.05$.

\section{Results}

\section{Patients and clinical data}

In total, 98 patients who underwent surgery due to colorectal adenocarcinoma were included in the study. Median age at the time of operation was 64 years. Mean overall survival was 55.5 months. Median follow-up time was 619 days. Twenty patients died during the follow-up. A detailed overview on patients' clinical characteristics is provided in Table 1.
Table I Overview of clinical parameters and expression of Smurf2

\begin{tabular}{|c|c|c|c|}
\hline \multirow[t]{2}{*}{ Patient characteristics } & \multirow[t]{2}{*}{$\mathbf{n}$} & \multicolumn{2}{|c|}{ Median expression } \\
\hline & & Smurf2 & $P$-value \\
\hline $\begin{array}{l}\text { Gender } \\
\text { Male } \\
\text { Female }\end{array}$ & $\begin{array}{l}57 \\
41\end{array}$ & $\begin{array}{l}1.729 \\
1.000\end{array}$ & $0.07 I$ \\
\hline $\begin{array}{l}\text { Age at operation } \\
\text { Median }<67 \text { years } \\
\text { Median } \geq 67 \text { years } \\
\end{array}$ & $\begin{array}{l}47 \\
51 \\
\end{array}$ & & 0.864 \\
\hline $\begin{array}{l}\text { T stage } \\
\text { TI } \\
\text { T2 } \\
\text { T3 } \\
\text { T4 } \\
\end{array}$ & $\begin{array}{l}1 \\
13 \\
68 \\
16\end{array}$ & $\begin{array}{l}- \\
0.888 \\
1.214 \\
1.028\end{array}$ & 0.682 \\
\hline $\begin{array}{l}\text { N stage } \\
\text { No } \\
\text { NI } \\
\text { N2 }\end{array}$ & $\begin{array}{l}45 \\
24 \\
29 \\
\end{array}$ & $\begin{array}{l}1.117 \\
1.568 \\
0.901 \\
\end{array}$ & 0.187 \\
\hline $\begin{array}{l}\text { M stage } \\
\text { MO } \\
\text { MI }\end{array}$ & $\begin{array}{l}63 \\
35 \\
\end{array}$ & $\begin{array}{l}1.006 \\
1.681 \\
\end{array}$ & 0.516 \\
\hline $\begin{array}{l}\text { M stage (MSS tumors) } \\
\text { M0 } \\
\text { MI }\end{array}$ & $\begin{array}{l}35 \\
23\end{array}$ & $\begin{array}{l}0.747 \\
1.474\end{array}$ & 0.024 \\
\hline $\begin{array}{l}\text { Tumor grade } \\
\text { GI } \\
\text { G2 } \\
\text { G3 } \\
\text { n/a }\end{array}$ & $\begin{array}{l}3 \\
63 \\
26 \\
6\end{array}$ & $\begin{array}{l}0.611 \\
1.205 \\
0.904 \\
0.767\end{array}$ & 0.893 \\
\hline $\begin{array}{l}\text { Colorectal liver metastases } \\
\text { Synchronous } \\
\text { Metachronous }\end{array}$ & $\begin{array}{l}31 \\
6\end{array}$ & $\begin{array}{l}1.474 \\
0.760\end{array}$ & 0.342 \\
\hline $\begin{array}{l}\text { Resection margin status } \\
\text { R0 } \\
\text { RI } \\
\text { R2 }\end{array}$ & $\begin{array}{l}89 \\
6 \\
3\end{array}$ & $\begin{array}{l}1.07 \mathrm{I} \\
\mathrm{I} .538 \\
2.770\end{array}$ & 0.909 \\
\hline $\begin{array}{l}\text { Tumor site } \\
\text { Sigmoid } \\
\text { Rectum } \\
\text { Rectosigmoid } \\
\text { Colon descendens } \\
\text { Colon transversum } \\
\text { Colon ascendens } \\
\text { Caecum } \\
\end{array}$ & $\begin{array}{l}21 \\
33 \\
4 \\
8 \\
2 \\
16 \\
14 \\
\end{array}$ & $\begin{array}{l}1.013 \\
1.000 \\
2.058 \\
1.687 \\
13.170 \\
1.330 \\
1.340 \\
\end{array}$ & 0.732 \\
\hline $\begin{array}{l}\text { Surgical procedure } \\
\text { High anterior resection } \\
\text { Low anterior resection } \\
\text { Sigmoidectomie } \\
\text { Left colectomy } \\
\text { Right colectomy } \\
\text { Abdominoperineal resection } \\
\text { Subtotal colectomy } \\
\text { Pelvic exenteration }\end{array}$ & \begin{tabular}{|l}
8 \\
26 \\
12 \\
14 \\
30 \\
5 \\
2 \\
1 \\
\end{tabular} & $\begin{array}{l}0.848 \\
0.936 \\
1.284 \\
1.687 \\
1.340 \\
1.071 \\
13.170 \\
- \\
\end{array}$ & 0.474 \\
\hline $\begin{array}{l}\text { Neoadjuvant therapy } \\
\text { Yes } \\
\text { No }\end{array}$ & $\begin{array}{l}13 \\
85\end{array}$ & $\begin{array}{l}1.125 \\
0.611\end{array}$ & 0.230 \\
\hline
\end{tabular}

(Continued) 
Table I (Continued)

\begin{tabular}{|l|l|l|l|}
\hline Patient characteristics & \multirow{2}{*}{} & \multicolumn{2}{|l|}{ Median expression } \\
\cline { 3 - 4 } & & Smurf2 & P-value \\
\hline Anastomotic leakage & 12 & 1.003 & 0.983 \\
Yes & 86 & 1.153 & \\
No & & & $0.006^{*}$ \\
\hline Microsatellite status & 58 & 0.898 & \\
MSS & 11 & 2.462 & \\
MSI & & & 0.320 \\
\hline Recurrence & 17 & 0.773 & \\
Yes & 81 & 1.117 & \\
No & &
\end{tabular}

Note: $P<0.05$ was considered statistically significant.

Abbreviations: MSI, microsatellite instable; MSS, microsatellite stable; n/a, not available.

\section{Quantitative expression of Smurf2 in colorectal cancer tissue and healthy mucosa}

Real-time PCR of CRC tissue and corresponding healthy mucosa revealed a significantly higher expression of Smurf2 in tumoral tissue than in healthy mucosa ( $P=0.003$ ) (Figure 1). We then correlated Smurf2 expression with patients' clinical data (Table 1). Interestingly, MSS ( $\mathrm{n}=58$ ) tumors displayed significantly lower expression of Smurf2 compared to MSI ( $\mathrm{n}=11)$ tumors ( $P=0.006)$ (Figure 2). No statistically significant correlations with tumoral Smurf2 expression were observed regarding other histopathological or clinical variables (Table 1).

\section{Spatial expression of Smurf2 in colorectal cancer tissue and healthy mucosa}

Immunohistochemical staining was performed in five patients in order to assess cellular localization of Smurf2 in CRC tissue and normal colon mucosa. Consistent with the quantitative expression analysis outlined above, Smurf2 was strongly expressed in the tumor cells, particularly in the cytoplasm, whereas healthy mucosa cells only showed a very weak expression of Smurf 2 (Figure 3).

\section{Prognostic impact}

Subsequently, we correlated tumoral Smurf2 expression data with patients' overall survival. For this purpose, patients were divided into two groups: patients with high tumoral Smurf2 expression (an expression of Smurf2 five times higher in the tumoral tissue than in corresponding healthy mucosa) and patients with low tumoral Smurf2 expression (an expression of Smurf2 less than five times in the tumoral tissue than in corresponding healthy mucosa). In the entire collective of patients ( $\mathrm{n}=98)$, mean overall survival was 55.5 months. When looking

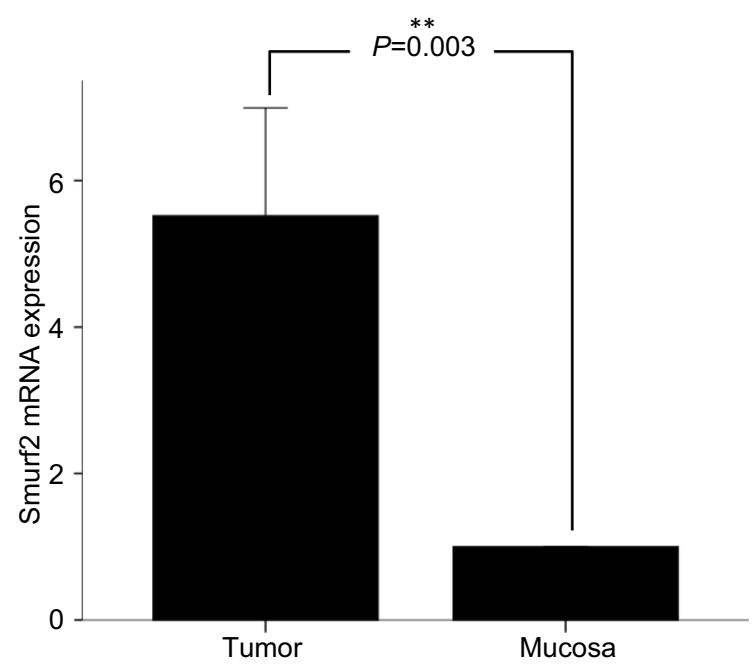

Figure I Transcript expression levels of Smurf2 in colorectal cancer tissue and corresponding healthy mucosa $(n=98)$.

Notes: Smurf2 was significantly overexpressed in colorectal cancer specimens compared to corresponding healthy mucosa. Bars represent mean + SEM. $* * P=0.003$. Abbreviation: SEM, standard error of the mean.

at the entire cohort, mean overall survival was 58 months for patients displaying high Smurf2 expression, compared to 52.9 months in patients with low tumoral Smurf2 expression ( $\mathrm{n}=98$ ) $(P=0.86$ ) (Figure 4A). Interestingly, in the subgroup of patients with MSS tumors $(\mathrm{n}=58)$, high tumoral expression of Smurf2 was significantly associated with impaired overall survival (mean overall survival high vs low Smurf2 expression 38.3 vs 67.4 months; $P=0.044$ ) (Figure 4B). By contrast, correlation of tumoral Smurf2 expression in patients with MSI tumors showed no influence on overall survival $(\mathrm{n}=11, P=0.41$ ). Subgroup analysis of MSS tumors revealed a significant two times higher median tumoral Smurf2 expression in M1 vs M0 staged patients ( $\mathrm{n}=58, P=0.024$; Figure 2B, Table 1$)$.

\section{Influence of Smurf2 on migration and invasion of SW-480 and DLD-I cells in vitro}

In vitro assays were conducted in order to assess the impact of Smurf2 expression on the invasive and migrative potential of CRC cells. For this purpose, we chose a MSS CRC cell line (SW-480) as well as a MSI cell line (DLD-1). Upon knockdown of Smurf2, we observed significantly diminished invasive $(P=0.012)$ and migrative $(P=0.011)$ properties of MSS SW-480 cells (Figure 5 A, B). MSI DLD-1 cells likewise displayed significantly reduced invasive potential $(P=0.013)$, but only insignificantly reduced migrative potential upon Smurf2 knockdown $(P=0.11)$ (Figure 5A, B). The mean transfection efficiency was $76 \%$ (range $73 \%-79 \%$ ) in SW-480 

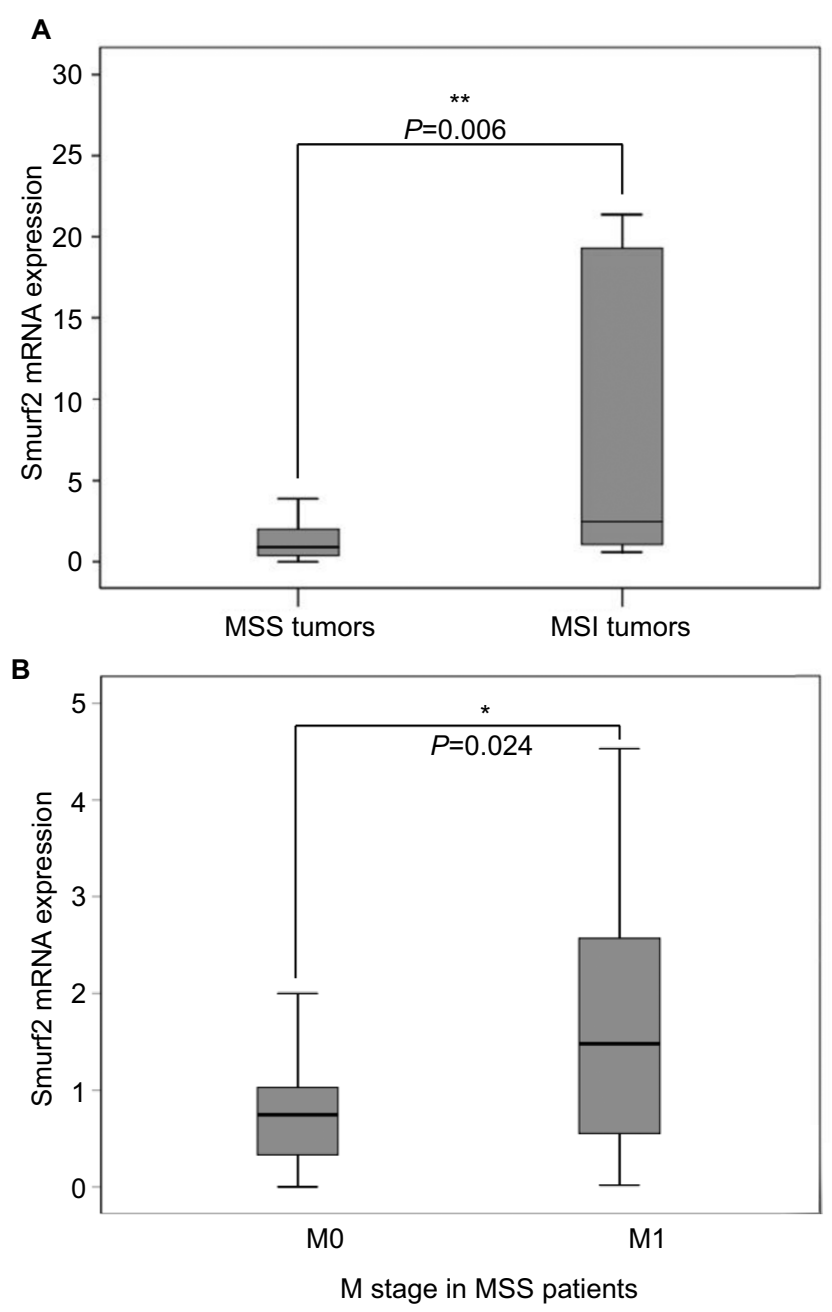

Figure 2 (A) Smurf2 expression dependent on patients' microsatellite status. Patients with microsatellite stable (MSS) tumors $(n=58)$ displayed a significantly lower expression of Smurf2 than patients with microsatellite instable (MSI) tumors $(\mathrm{n}=\mathrm{I}$ I; $P=0.006)$. (B) Within the 58 MSS tumors, Smurf2 expression was significantly higher in $\mathrm{MI}$ staged patients vs $\mathrm{M0}(P=0.024)$. cells and $64.3 \%$ (range $52 \%-84 \%$ ) in DLD-1 cells for the migration assays. For the invasion assays, mean transfection efficiency was $81.3 \%$ (range $73 \%-92 \%$ ) in SW-480 cells and $85.3 \%$ (range $84 \%-88 \%$ ) in DLD-1 cells.

Collectively, these findings suggest that Smurf2 expression enhances the invasive and migrative properties of CRC cells.

\section{Discussion}

To our knowledge, this is the first study evaluating the prognostic impact of the E3 ubiquitin ligase Smurf2 in CRC patients. We detected significantly enhanced expression of Smurf2 in CRC tissue compared to corresponding healthy colon mucosa, as well as significantly attenuated expression of Smurf2 in MSS compared to MSI tumors. Intriguingly, high-level Smurf2 expression represented an adverse prognostic factor in patients with MSS tumors. In vitro, interference with Smurf2 expression was associated with impaired migrative and invasive proficiency of CRC cells. These findings indicate that Smurf2 could be a prognostic marker in MSS CRC patients.

Targeted degradation of proteins by the UPS is crucial for diverse biological processes such as cell-cycle progression, apoptosis, angiogenesis, stem cell quiescence, signal transduction, and transcriptional regulation. ${ }^{13,14}$ Expressional changes, dysfunction, and genetic alterations of substratespecific E3 ubiquitin ligases are known to provoke cancer. ${ }^{2}$ The E3 ubiquitin ligase Smurf2 is located on chromosome 17 and exhibits, contrary to Smurf1, only one isoform. It possesses a C2 domain, a C-terminal HECT domain, and three central WW protein-interacting domains, of which second
A

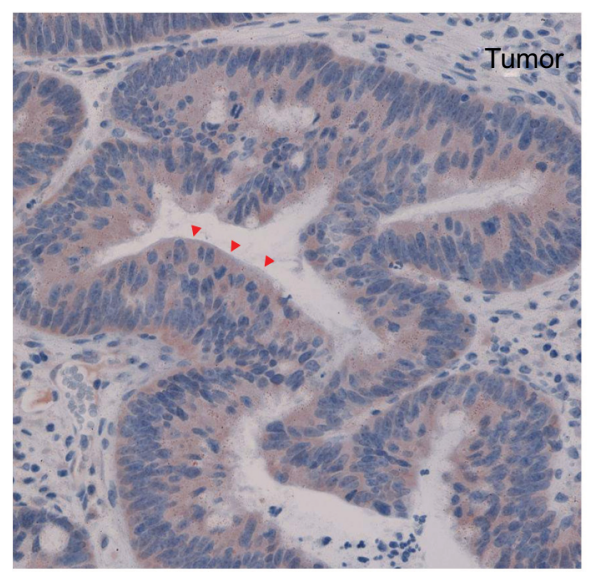

B

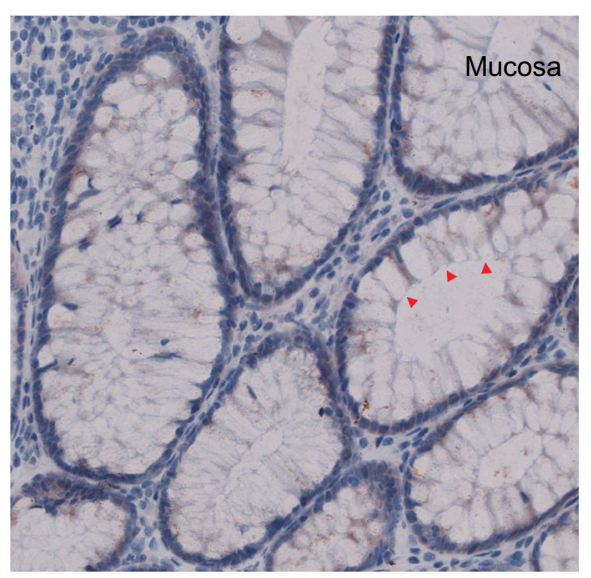

Figure 3 Representative immunohistochemistry revealing spatial localization of Smurf2 protein (40 $\times$ magnification).

Notes: Smurf2 was strongly expressed in the tumor cells (A), particularly in the cytoplasm (arrowheads), whereas healthy mucosa cells (B) only showed a very weak expression of Smurf 2. 

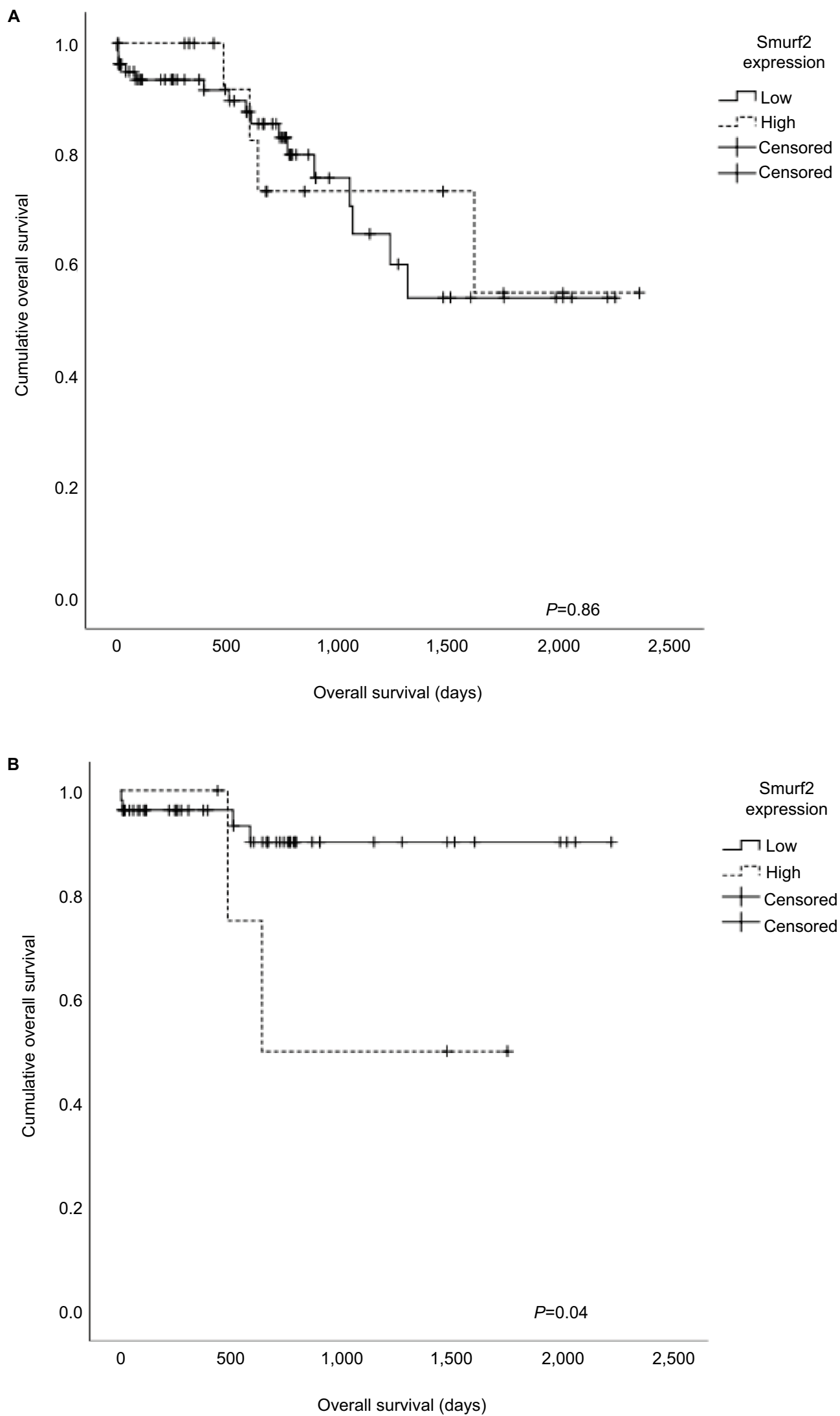

Figure 4 (A) Correlation of Smurf2 expression and overall survival of the entire patient cohort revealed no significant difference between Smurf2 high and Smurf2 low tumors $(n=98)(P=0.86)$. (B) Correlation of Smurf2 with microsatellite status and overall survival. Overall survival was significantly impaired in microsatellite stable (MSS) patients expressing high levels of Smurf2 $(n=58)(* P=0.044)$. 

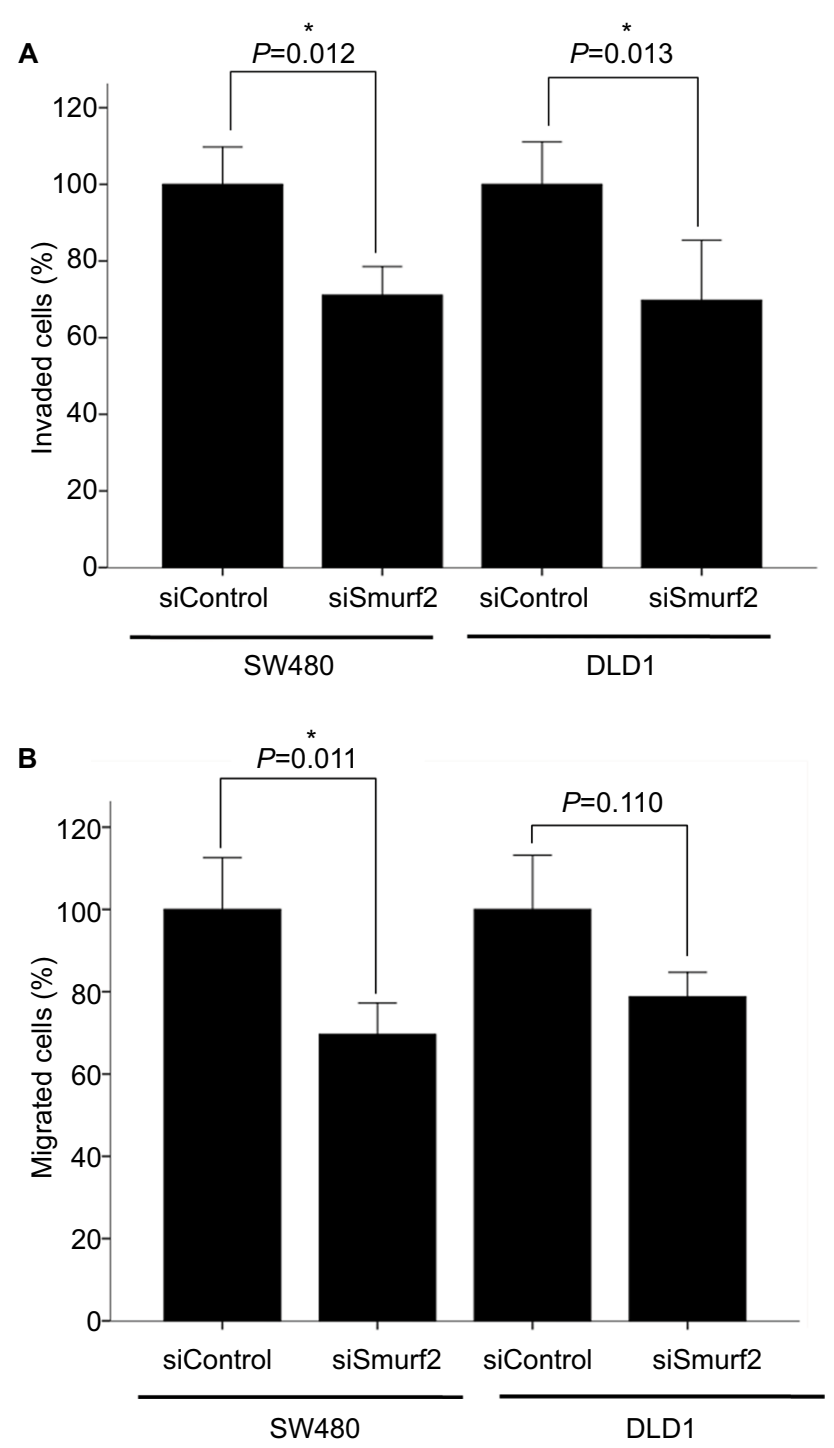

Figure 5 Invasion (A) and migration (B) assays.

Notes: Smurf2 siRNA-transfected SW-480 cells were both significantly less invasive $(* P=0.012)$ and migrative $(* P=0.01 I)$; DLD-I cells revealed significantly reduced invasive potential $(* P=0.013)$. Bars represent mean $+S E M$.

Abbreviation: SEM, standard error of the mean.

and third are responsible for target recognition. ${ }^{3}$ Dependently on its particular targets, Smurf2 can induce different signaling pathways - either oncogenic or tumorsuppressive.

On the cellular level, Smurf2 is able to transfer between the nucleus and the cytoplasm: after interacting with Smad6/Smad7 inside the nucleus, the Smurf2/Smad complex shuttles to the cytoplasm to target specific substrates. ${ }^{3}$ Immunohistochemical staining applied in our present study revealed expression of Smurf2 protein predominantly in the cytoplasm of CRC cells, indicating activated complex formation enabling further substrate binding and active signaling. Importantly, quantitative expression analysis revealed overexpression of Smurf2 in CRC tissue compared to healthy colon mucosa. This is consistent with some previous reports on Smurf2 expression in solid cancers: For instance, Fukuchi et al described overexpression of Smurf2 in esophageal squamous cell carcinoma. ${ }^{11}$ By contrast, downregulation of Smurf2 is a hallmark of triple-negative breast cancers - but not of hormone receptor-positive breast cancers. ${ }^{15}$ Hellwinkel et al reported higher Smurf2 expression in T2 than in T3 prostate cancer, indicating that loss of Smurf2 facilitates tumor progression. ${ }^{16}$ In concert with these previous reports, our present findings emphasize on putatively dual role of Smurf2 in cancer progression, which is most likely due to activation of different signaling pathways in various tumor entities and individual patient settings.

Our current in vitro analysis links expressional downregulation of Smurf 2 to diminished migrative and invasive potential of CRC cells. This phenomenon was independently observed in two established CRC cell lines and pronounced in the MSS SW-480 cell line. It is thus conceivable that Smurf2 facilitates metastatic properties of CRC cells, at least in MSS CRC. In accordance with these findings, David et al observed attenuated proliferative, migrative, and invasive properties after Smurf2 knockdown in MCF-7 (estrogen receptor [ER] positive) and MDA-MB-231 (ER negative) breast cancer cells, which was mediated by the Smurf2 target protein connector enhancer of kinase suppressor of ras 2 (CNKSR2) via PI3K-PTEN-AKT signaling. ${ }^{7}$ Moreover, Smurf2 reportedly fosters migration and invasion of breast cancer cells through upregulation of the epithelial-mesenchymal transition marker $\mathrm{N}$-cadherin. ${ }^{12}$ Consistent with these pro-oncogenic functions of Smurf2, Fukuchi et al associated high-level expression of Smurf2 with increased invasion and lymph node metastases in esophageal squamous cell carcinoma. ${ }^{11}$

In our present study, we did not detect an association between Smurf2 expression in human CRC tissues and clinical TNM stages. However, Smurf2 expression was significantly elevated and associated with a wider range in MSI as compared to MSS tumors, hinting the fact that MSI tumors of CRC with DNA replication errors and defective mismatch repair have distinct phenotypic features in contrast to MSS tumors. ${ }^{17} \mathrm{~A}$ relevant proportion of about $15 \%$ of CRC display microsatellite instability due to deficient DNA mismatch repair. About 3\% of those are associated with a hereditary context such as Lynch syndrome, whereas $12 \%$ occur as sporadic CRCs. ${ }^{18-20}$ MSI/MSS status by itself is a predictor of prognosis in CRC patients, ${ }^{21}$ albeit its prognostic impact varies. ${ }^{22-24}$ In general, better prognosis is reported in patients with MSI compared to those with MSS CRC, ${ }^{22}$ 
but conflicting evidence likewise exists: Shin et al identified MSI as an independent prognostic factor, associated with impaired survival in stage II CRC, ${ }^{23}$ and Mohan et al reported reduced disease-specific survival in stage III MSI CRC. ${ }^{25}$ Given these discordant observations, it appears conceivable that the prognostic impact of patients' MSI status varies, dependently on the expression of alternative tumoral signaling pathways. Remarkably, in this context, we found that high tumoral expression of Smurf2 was associated with impaired survival in patients with MSS CRC, but not in those with MSI CRC. Second, within MSS CRC, a significant elevation of Smurf2 expression was found in M1 staged patients. This can be explained as the decrease in invasion of the MSI cell line DLD-1 might correlate with patients T stage as a surrogate for invasiveness, but in vivo, the $\mathrm{T}$ stage did not show differences in Smurf2 expression ( $P=0.682$, Table 1). Furthermore, migration of the MSI cell line DLD-1 showed no significant difference after Smurf2 knockdown whereas the MSS cell line SW-480 showed both significant differences in invasion and migration. In general, locally advanced CRC correlate with impaired overall survival, but in our data, no influence on Smurf2 expression within different T stages in MSI CRC could be proven. This could be due to the small number of deaths in subgroup analysis, which is a potential weakness of our analysis. Another possibility is that invasiveness in vivo is regulated in a much more complex manner and Smurf2 expression alone cannot represent this adequately for MSI tumors. However, the influence of Smurf2 in MSS CRC on M stage and overall survival is consistent with our in vitro data outlined above, which revealed significantly reduced invasion and migration upon expressional silencing of Smurf2 particularly in an MSS CRC cell line.

Though the oncogenic potential of the E3 ubiquitin ligase Smurf2 has been proven, ${ }^{3}$ studies linking the impact of Smurf2 expression to overall survival in individual tumor entities have remained scarce. Collectively, the results outlined in this study indicate a prognostic role of Smurf2 in MSS CRC patients. However, further studies are necessary to evaluate the oncogenic and pro-metastatic properties of Smurf2 dependently on patients' microsatellite status as well as underlying molecular mechanisms.

\section{Conclusion}

We suggest an oncogenic role of E3 ubiquitin ligase Smurf2 in MSS CRC. Moreover, upregulated Smurf2 affects survival - dependent on patients' MSI status - indicating its prognostic impact.

\section{Acknowledgment}

This work was supported by a grant from the Clinical Research Unit KFO 227: "From primary tumor progression towards metastases" funded by the German Research foundation (DFG).

\section{Author contributions}

All authors contributed to data analysis, drafting or revising the article, gave final approval of the version to be published, and agree to be accountable for all aspects of the work.

\section{Disclosure}

The authors report no conflicts of interest in this work. The abstract of this paper titled "Smurf2 - an invasive and oncogenic E3-ubiquitin ligase in colorectal cancer" was presented at the 20th Surgical Research Days, Section of Surgical Research of the German Society of Surgery, September 2016, Magdeburg, Germany as a conference talk with interim findings. The abstract only was published in European Surgical Research, 2016, Vol. 57; p.288; DOI 10.1159/000448816.

\section{References}

1. Nakayama KI, Nakayama K. Ubiquitin ligases: cell-cycle control and cancer. Nat Rev Cancer. 2006;6(5):369-381.

2. Bernassola F, Karin M, Ciechanover A, Melino G. The HECT family of E3 ubiquitin ligases: multiple players in cancer development. Cancer Cell. 2008;14(1):10-21.

3. David D, Nair SA, Pillai MR. Smurf E3 ubiquitin ligases at the cross roads of oncogenesis and tumor suppression. Biochim Biophys Acta. 1835;2013(1):119-128.

4. Zhang Y, Chang C, Gehling DJ, Hemmati-Brivanlou A, Derynck R. Regulation of Smad degradation and activity by Smurf2, an E3 ubiquitin ligase. Proc Natl Acad Sci USA. 2001;98(3):974-979.

5. Kavsak P, Rasmussen RK, Causing CG, et al. Smad7 binds to Smurf2 to form an E3 ubiquitin ligase that targets the TGF beta receptor for degradation. Mol Cell. 2000;6(6): 1365-1375.

6. Blank M, Tang Y, Yamashita M, Burkett SS, Cheng SY, Zhang YE. A tumor suppressor function of Smurf2 associated with controlling chromatin landscape and genome stability through RNF20. Nat Med. 2012;18(2): 227-234.

7. David D, Jagadeeshan S, Hariharan R, Nair AS, Pillai RM. Smurf2 E3 ubiquitin ligase modulates proliferation and invasiveness of breast cancer cells in a CNKSR2 dependent manner. Cell Div. 2014;9:2.

8. Nie J, Xie P, Liu L, et al. Smad ubiquitylation regulatory factor $1 / 2$ (Smurf1/2) promotes p53 degradation by stabilizing the E3 ligase MDM2. J Biol Chem. 2010;285(30):22818-22830.

9. Bonni S, Wang HR, Causing CG, et al. TGF-beta induces assembly of a Smad2 -Smurf2 ubiquitin ligase complex that targets SnoN for degradation. Nat Cell Biol. 2001;3(6):587-595.

10. $\mathrm{Xu} \mathrm{Y,} \mathrm{Pasche} \mathrm{B.} \mathrm{TGF-beta} \mathrm{signaling} \mathrm{alterations} \mathrm{and} \mathrm{susceptibility} \mathrm{to}$ colorectal cancer. Hum Mol Genet. 2007;16 Spec No 1:R14-R20.

11. Fukuchi M, Fukai Y, Masuda N, et al. High-level expression of the Smad ubiquitin ligase Smurf2 correlates with poor prognosis in patients with esophageal squamous cell carcinoma. Cancer Res. 2002;62(24):7162-7165.

12. Jin C, Yang YA, Anver MR, Morris N, Wang X, Zhang YE. Smad ubiquitination regulatory factor 2 promotes metastasis of breast cancer cells by enhancing migration and invasiveness. Cancer Res. 2009;69(3):735-740. 
13. Ingham RJ, Gish G, Pawson T. The Nedd4 family of E3 ubiquitin ligases: functional diversity within a common modular architecture. Oncogene. 2004;23(11):1972-1984

14. Inoue Y, Imamura T. Regulation of TGF- beta family signaling by E3 ubiquitin ligases. Cancer Sci. 2008;99(11):2107-2112.

15. Subramaniam V, Li H, Wong M, et al. The RING-H2 protein RNF11 is overexpressed in breast cancer and is a target of Smurf $2 \mathrm{E} 3$ ligase. $\mathrm{Br}$ $J$ Cancer. 2003;89(8):1538-1544.

16. Hellwinkel OJ, Asong LE, Rogmann JP, et al. Transcription alterations of members of the ubiquitin-proteasome network in prostate carcinoma. Prostate Cancer Prostatic Dis. 2011;14(1):38-45.

17. Kim H, Jen J, Vogelstein B, Hamilton SR. Clinical and pathological characteristics of sporadic colorectal carcinomas with DNA replication errors in microsatellite sequences. Am J Pathol. 1994;145(1):148-156.

18. Boland CR, Goel A. Microsatellite instability in colorectal cancer Gastroenterology. 2010;138(6):2073-2087.e3.

19. Jasperson KW, Tuohy TM, Neklason DW, Burt RW. Hereditary and familial colon cancer. Gastroenterology. 2010;138(6):2044-2058.
20. Ahadova A, Gallon R, Gebert J, et al. Three molecular pathways model colorectal carcinogenesis in Lynch syndrome. Int J Cancer. 2018;143(1):139-150.

21. Sinicrope FA, Sargent DJ. Molecular pathways: microsatellite instability in colorectal cancer: prognostic, predictive, and therapeutic implications. Clin Cancer Res. 2012;18(6):1506-1512.

22. Popat S, Hubner R, Houlston RS. Systematic review of microsatellite instability and colorectal cancer prognosis. J Clin Oncol. 2005;23(3):609-618.

23. Shin US, Cho SS, Moon SM, et al. Is microsatellite instability really a good prognostic factor of colorectal cancer? Ann Coloproctol. 2014;30(1):28-34.

24. Webber EM, Kauffman TL, O’Connor E, Goddard KA. Systematic review of the predictive effect of MSI status in colorectal cancer patients undergoing 5FU-based chemotherapy. BMC Cancer. 2015;15:156.

25. Mohan HM, Ryan E, Balasubramanian I, et al. Microsatellite instability is associated with reduced disease specific survival in stage III colon cancer. Eur J Surg Oncol. 2016;42(11):1680-1686.
Cancer Management and Research

\section{Publish your work in this journal}

Cancer Management and Research is an international, peer-reviewed open access journal focusing on cancer research and the optimal use of preventative and integrated treatment interventions to achieve improved outcomes, enhanced survival and quality of life for the cancer patient. The manuscript management system is completely online and includes

\section{Dovepress}

a very quick and fair peer-review system, which is all easy to use. Visit $\mathrm{http}: / /$ www.dovepress.com/testimonials.php to read real quotes from published authors. 